\title{
Los retos de la economía colombiana para 2018
}

$\mathrm{L}$ os objetivos de la política económica para el 2018 en Colombia, en cuanto al crecimiento económico, el desempleo, la inflación y el sector externo, plantean algunos factores favorables, pero, también, incertidumbre y limitaciones de todo orden.

En lo relativo al crecimiento económico, la meta de 2,5 por ciento fijada para el año 2017, no se alcanzará, ya que el comportamiento de los tres trimestres transcurridos indica que, escasamente, llegará al 1,8 por ciento.

El Gobierno nacional ha proyectado una meta de crecimiento para el 2018 de 3 por ciento, mientras que el Fondo Monetario Internacional (FMI) lo estima en 2,8 por ciento y el Banco de la República lo calcula en 2,7 por ciento. Estos guarismos, mejores que los de 2017, se explican por varias razones, entre las que cabe destacar: se espera que el impacto causado por las nuevas tarifas del IVA (que pasó del 16 por ciento al 19 por ciento) no sea tan fuerte para el 2018; también se espera que la inflación, que en lo corrido del período (enero-octubre de 2017) se ubica en 3,5 por ciento, siga bajando el próximo año; y la tasa de interés, que se redujo de 7,5 por ciento en diciembre de 2016 a 4,75 en noviembre del presente año. Tanto el ministro de Hacienda como el gerente del Banco de la República prevén que siga descendiendo hasta situarse, a mediados del año entrante, en 4 por ciento. Se confía en que los factores anteriormente descritos induzcan al sector privado a incrementar el gasto en 2018.

En lo que concierne al sector público, las expectativas para 2018 son difíciles, debido a la vigencia de la ley de garantías y al previsible apretón fiscal del Gobierno. El presupuesto general de la nación solo creció el 1 por ciento y está aforado en \$235,6 billones. La inversión pública decreció en 2,8 por ciento con relación al monto del presente año y solo fueron asignados $\$ 40$ billones.

Con relación al desempleo, y debido, en buena parte, al bajo crecimiento, en septiembre alcanzó 9,2 por ciento (siendo el año anterior de 8,5 por ciento). Se anticipa que las expectativas son inciertas. Es evidente que el problema del desempleo inquieta a cualquier país, dado que a medida que alcanza niveles altos, deja de ser una preocupación estrictamente económica, para ser, también, social. En lo corrido del año (octubre de 2017) es la rama de agricultura, ganadería, caza, silvicultura y pesca, la que ha impulsado la generación de empleo. Así mismo, las actividades inmobiliarias, empresariales y de alquiler, y los servicios comunales, sociales y personales, son las ramas que más han contribuido a la ocupación en Colombia.

De hecho, las expectativas en sectores que son intensivos en la utilización de mano de obra, como el sector de la construcción, tanto de edificaciones como de obras civiles, se ha estancado y se espera un repunte para el próximo año. En el caso de edificaciones, como también 
para el sector industrial, se prevé que entren en pleno vigor los programas Plan de Impulso a la Propiedad (PIPE), en sus dos versiones, y el de Colombia Repunta. Por otra parte, en el caso de obras civiles, se espera que la aprobación de la ley de infraestructura, consistente en la adopción del "pliego tipo" obligatorio, y además, la autorización del Banco de la República para que las entidades financieras extranjeras puedan otorgar créditos a las concesiones en pesos, dinamicen dicha actividad.

En cuanto a la inflación, los resultados para este año y las expectativas para el próximo son favorables; la inflación para 2017 va a estar dentro del rango meta a largo plazo (2-4 por ciento), y los pronósticos para 2018 son tan optimistas que el gerente del Banco de la República vaticina que este indicador será de, aproximadamente, 3 por ciento. Sin duda, el factor determinante en la reducción de la inflación ha sido el comportamiento favorable de los alimentos, además de la reducción de la tasa de interés. No obstante el fin del conflicto armado y los acuerdos de paz firmados con las Fuerzas Armadas Revolucionarias de Colombia (FARC), hoy convertidas en el partido político Fuerza Alternativa Revolucionaria del Común (FARC), que han generado un clima de tranquilidad en el campo, lo determinante en la producción agrícola han sido las condiciones climáticas. Este último componente es aleatorio y no es fácil realizar pronósticos concluyentes.

Por último, el déficit en cuenta corriente se aproxima al 4 por ciento del PIB, resultado de la mejoría, en los últimos meses, de los precios tanto del petróleo como del carbón, que han contribuido a incrementar el valor de las exportaciones. El petróleo de referencia Brent ha repuntado desde agosto del presente año hasta cotizarse el 6 de noviembre en 64,27 dólares el barril, y el carbón ha subido desde abril, y su precio, para la misma fecha, era de 85 dólares la tonelada.

Es sabido que los determinantes de las exportaciones son la tasa de cambio y el comportamiento de la economía mundial. Con relación al primer factor, puede pensarse que el año entrante el proceso de devaluación del peso afectará positivamente a las exportaciones, y, en cuanto a la evolución de la economía mundial, se espera un mayor dinamismo de la misma, en especial de los principales socios comerciales, Estados Unidos y los países latinoamericanos, lo que, sin duda, estimulará las exportaciones a dichos países.

En términos generales, se puede afirmar que las proyecciones económicas para el próximo año son favorables. Sin embargo, no hay que olvidar que 2018 será un año electoral y que de una u otra forma influirá en la confianza de los agentes económicos y en sus decisiones como consumidores o inversionistas. Aunque el ministro de Hacienda considera que el cambio de gobierno no debe provocar alteraciones considerables, lo cierto es que la situación actual es sui generis, en la medida en que es la primera vez que en un proceso electoral participan las FARC como movimiento político legal, a pesar del ambiente político de polarización, en el que movimientos y grupos políticos de izquierda, centro y derecha se confrontan para ganar adeptos. Dada esta situación, es posible que muchos empresarios, tanto nacionales como extranjeros, aplacen sus proyectos de inversión hasta que se despeje el panorama electoral y se conozca el modelo económico del próximo Gobierno.

Luis E. Vallejo Zamudio Director Revista Apuntes del Cenes 